\title{
ESPESSURA DO CIRCUITO DE RADIO FM EM CAMPINAS
}

\section{THICKNESS OF THE RADIO FM CIRCUIT IN CAMPINAS}

\author{
Cristiano Nunes Alves \\ Universidade Estadual de Campinas \\ cris7cris7@yahoo.com.br
}

\begin{abstract}
RESUMO
Neste artigo analisamos a conformação e a espessura do circuito de rádio FM em Campinas. O circuito FM se insere no campo da indústria cultural em especial desde a década de 1970, tendo se expandido num momento de aceleração do processo de urbanização brasileira. Hoje este circuito integra um aparelho maior, ligado a estratégias verticais de uso do território. Trata-se, pois, de um estudo de Campinas enquanto um lugar que abriga densidades técnica, informacional e comunicacional. Problematizamos as condições geográficas contemporâneas de vida nesta cidade, indagando sobre a existência e o espraiamento de circuitos ascendentes de informação no território usado. Palavras chave: Urbanização - Comunicação - Informação - Música - Campinas
\end{abstract}

\begin{abstract}
This paper examines the formation and the thickness of the circuit of radio FM in Campinas. The circuit FM in Campinas falls in the field of cultural industry since de decade of 1970, and has been expanding in the context of urbanization and metropolis growing in Brazil. Today this circuit incorporates a bigger system, coupled with the strategies of vertical use of the territory. It is, therefore, a study of Campinas as a place that houses technical, informational and communicational densities. We analyzed geographical conditions of contemporary life in this city, inquiring about the communication component in the use of the territory.

Key words: Urbanization - Communication - Information - Music - Campinas.
\end{abstract}




\section{Introdução}

Com significativa densidade técnica-informacional, e entre as cidades mais importantes do estado de São Paulo, Campinas abriga atualmente cerca de 1.100.000 habitantes (Instituto Brasileiro de Geografia e Estatística- IBGE, 2012). Caracterizada pela desigualdade socioterritorial, sua região é importante elo informacional, polo industrial e tecnológico intensamente ligado à metrópole paulista.

Num contexto de urbanização do território e no mesmo compasso do crescimento do mercado fonográfico nacional, desponta desde meados da década de 1970 o circuito de rádio FM campineiro. Trata-se do ensejo no qual se delineia a centralidade das emissoras oficiais (concessionadas) na difusão massiva da produção fonográfica. A partir daí, entendemos que se espraia "a influência no circuito sonoro", uma importante variável do território atual.

A constituição e o movimento do circuito sonoro implicam na apropriação no uso de praças, bares, ruas, objetos técnicos de informação - desde rádios até telefones celulares - estúdios de produção fonográfica, emissoras de rádio, satélites informacionais, lojas de tecnologia de gravação, entre outros. Sua dinâmica envolve o registro material da produção fonográfica, as mediações das experiências cotidianas ligadas à música e o fluxo de informações criado, que perpassa a produção musical, os eventos musicais e todo o contato entre os agentes envolvidos.

$\mathrm{O}$ circuito de rádio FM traz à tona um momento desse circuito maior, cada vez mais cerceado pelos ditames da indústria cultural "um sistema" invasor das consciências (ADORNO, 2004: 7) e orientador das experiências sonoras dos micro-circuitos nos lugares.

A abordagem do circuito sonoro em Campinas corresponde ao estudo geográfico da música, produzida e difundida no emaranhado meio urbano, tema, ao que tudo indica premente de aprofundamento em nossa disciplina (ROMAGNAN, 2000; CLAIRE, 2006; MARTIGNONI, 2006). 


\section{Objetivos e metodologia utilizada}

Neste artigo, primeiramente abordamos o rompimento entre origem e alcance de transmissão sonora, configurando um "meio esquizofônico". Entre os conteúdos desse novo período, marcado por uma base técnica adequada à transmissão do componente informacional, destacamos a radiodifusão FM. Por meio deste veículo, ideal para a transmissão musical, um repertório clichê e uma constante de informações medianas (baseadas em padrões) são impostos, como parte eficaz da "catequese musical" na cidade contemporânea.

Num segundo momento inventariamos o circuito das rádios FM concessionadas em Campinas. Abordamos certos componentes geográficos envolvidos na radiodifusão para dar subsídio a apresentação dos aspectos produtivos da empresa do rádio nesta cidade e a discussão sobre a repercussão espacial deste circuito radiodifusor.

Para inventariar o circuito FM em Campinas, além do levantamento bibliográfico e documental sobre a temática, presente, entre outros, em livros, material cartográfico e audição da programação das emissoras, foram fundamentais os trabalhos de campo, reunindo dessa forma, um importante "campo de informação primário." Nessa via, realizamos 1) visitas técnicas a todas as 16 emissoras concessionadas do circuito FM campineiro 2) entrevistas junto a programadores, locutores, técnicos de radiodifusão, vendedores de anúncios publicitários, repórteres, produtores culturais, editores, entre outros, obtendo, considerável conjunto de informações primárias, além de catálogos de anunciantes, relatórios técnicos e materiais promocionais das emissoras. Trataram-se de entrevistas semi-estruturadas, baseadas em roteiros maleáveis e diálogos abertos, todavia procurando aclarar a dinâmica interna das emissoras de rádio: seus sistemas técnicos e fluxos embutidos, bem como a articulação desses meios de informação com agentes tais quais anunciantes, artistas, gravadoras e agências de publicidade.

\section{Território e informação: meio esquizofônico e radiodifusão}

Desde o telégrafo, e pouco depois com o rádio e o registro fonográfico, delineiase o fenômeno da esquizofonia (SCHAFER, 1997 [1977]): o rompimento entre a origem 
e a emissão sonora, fenômeno inserido num conjunto de transformações de sistemas técnicos que, compreendem ainda o cinema; são dados ativos constituidores e impulsionadores de uma revolução no tempo livre (FRIEDMANN, 1968), dispensando a presença humana para a ação e a transmissão de informações.

No meio esquizofônico a relação entre a proximidade e a distância se mostra cada vez mais uma variável administrada, produtora e produzida por um comando remoto de poder. Ocorrem importantes elos corporativos, que em diversos casos constituem a natureza das relações de interdependência entre os lugares.

Neste sentido, Pred (1979) trabalha o conceito de sistema de cidades, um sistema social complexo formado por um conjunto de cidades, seja ele regional ou nacional, no qual, por meio dos fluxos de informação, as mudanças em um lugar implicam num corpo de mudanças alhures. Por sua vez, Raffestin (1993) assinala que a informação encontra na capital um território de controle, de chegada e de partida para si.

Em nossa abordagem do circuito de FM destacamos a densidade informacional gerada em torno da difusão. De acordo com Santos (1999; 2004 [1996]) o acontecer dos lugares pode ser estudado a partir dos elementos relacionados à espessura dos contatos e transmissões de informação. O circuito de FM é um retrato do modo como os grandes grupos de informação produzem hierarquicamente uma série de escalas e usam o território.

O alcance potencialmente ilimitado trazido pela difusão das inovações esquizofônicas criou uma nova espessura de relações entre os lugares, mobilizando estratégias para o grande capital, mediante a adoção de inovações que o propiciem a agir em simultaneidade, administrando a variável tempo.

Todavia, da comunicação entre os indivíduos acreditamos emergir formas de pensar e agir no território a partir de uma racionalidade alternativa à racionalidade hegemônica. A informação e a comunicação têm capacidade de ordenação social e assim guardam "uma função política no sentido da constituição ou formação da polis" (SODRÉ, 1976: 19), ou seja, são entes de fundamental importância no contexto urbano contemporâneo. Daí a nossa inquietude para com a compreensão do papel da comunicação no período em curso.

\section{O rádio e a cisão territorial: a catequese musical}

Geo UERJ. Rio de Janeiro - Ano 16, no. 25, v.2, $2^{\circ}$ semestre de 2014, pp.209-230

ISSN: 1415-7543 E-ISSN: 1981-9021

http://www.e-publicacoes.uerj.br/index.php/geouerj 
O adestramento e a imposição musical de práticas consideradas impuras vêm de longa data em território nacional. No Brasil durante o período colonial, num meio em que os conteúdos informacionais acionados e transmitidos se manifestavam necessariamente pela presença humana, foram os padres os primeiros a ensinar música. Nesse contexto, tratava-se de uma maneira de doutrinar os nativos, introjetar-lhes um som e uma mensagem descendente, pois estranha às suas existências. Por meio da dança e dos sons, afirma Heitor (1945: 143) "foi sendo conquistado para Cristo o rebanho selvagem." Iniciava-se assim, a catequese musical, difundida a partir de colégios jesuítas, alcançando os povoados dos nativos.

Com a radiodifusão, a catequese musical toma outro sentido e se espraia para uma série de lugares. Os processos relacionados à temática indicam que Campinas, desde a chegada do fenômeno esquizofônico, dispõe de uma base técnica adequada à difusão do componente informacional (MARIANO, 1972; GEIGER, 1963).

Ortiz (1989) pontua a importância do rádio para a introdução da indústria cultural no país; nesse mesmo sentido Antongiovanni (1999: 40) ressalta que a partir de década de 1940 as rádios entram definitivamente na era da publicidade passando a ser “financiadas por agências de publicidade estrangeiras". Caldas (1995) explica que a publicidade fez com que o nível de audiência passasse a ser um dado vital para as emissoras. Como não havia pesquisa de audiência e mercado, a emissora devia ficar conhecida de uma maneira ou de outra, o que implicou no assalto da cidade pelo circuito de rádio:

...surgem os cartazes publicitários das emissoras dentro dos bondes, dos trens, dos ônibus, nas ruas e praças públicas, enfim, nos lugares de grande concentração e passagem de pedestres. Nos matutinos a propaganda das emissoras era quase diariamente obrigatória. (CALDAS, 1995: 54).

Eis então que se esboça o adensamento do circuito em torno da música popular e surgem as primeiras associações entre a imprensa escrita e a falada. Trata-se da chamada época do ouro do rádio no Brasil.

$\mathrm{Na}$ época, o Ministério da Educação, preconizava a importância do veículo como elemento de homogeneização cultural e formação de opinião pública, defendendo 
o seu uso por meio de zonas irradiadoras de cultura, inseridas num sistema com rádios controladas e oficiais (SALGADO, 1941). Nessa ótica o rádio era tido como um meio para conquistar "os indivíduos analfabetos, broncos, rudes de nossas cidades" (Idem: 84) e domesticar os "ritmos selvagens" como o samba: "tentemos, devagarinho tornálo mais educado e social" (...) "não repudiemos esse nosso irmão pelos defeitos que contém" (SALGADO, 1941: 86).

Goldmann (1972) pondera que a atividade cotidiana, nascedouro e abrigo da consciência, alicerce secular da vida cultural, encontra-se ameaçada pela evolução contemporânea das sociedades industriais. A partir das ações de enfraquecimento desenvolvidas pelos meios de massa, afirma o autor supracitado, presenciamos a “desculturalização pela desorganização dos receptores” (GOLDMANN, 1972: 26).

À cooperação e ao trabalho criativo conjunto impõem-se formatos e desdobramse cisões no território. Schafer (1997 [1977]) adverte que a maciça presença do rádio causa um grande contraste com os ritmos da vida. Para o autor antes as paredes isolavam os sons, mas hoje são os sons que servem para isolar, tornando-se a radiodifusão uma continua parede sonora. A noção de parede sonora proposta pelo autor nos será útil no entendimento das esferas de poder relacionadas ao rádio, que sob práticas corporativas, invariavelmente, conduz aos totalitarismos.

\section{A radiodifusão no território brasileiro}

Os dados e apontamentos a seguir nos dão idéia da quantidade e complexidade de objetos e ações movimentados em torno desse meio de informação hoje no Brasil e de seu papel no circuito sonoro. Entre os anos de 1977 e 1999 o número de emissoras de rádio quadruplicou no país: de 711 para 2.986, o segundo maior número de emissoras no mundo, depois dos Estados Unidos.

Santos \& Silveira (2005 [2001]: 241) destacam que hoje "graças a inovações tecnológicas o Brasil estaria em condições de duplicar o número de emissoras". Os autores lembram que $42 \%$ do total de emissoras FM se concentram no Estado de São Paulo, que abriga 548 delas (21\%). Em seguida aparecem Minas Gerais e Rio Grande do Sul, com 369 e 330 emissoras, respectivamente.

Trata-se do veículo de massa que abrange o maior número de lugares. De acordo Geo UERJ. Rio de Janeiro - Ano 16, nº. 25, v.2, $2^{\circ}$ semestre de 2014, pp.209-230 ISSN: 1415-7543 E-ISSN: 1981-9021 http://www.e-publicacoes.uerj.br/index.php/geouerj 
com o Ministério das Comunicações, em 2004, dos 4.974 municípios da federação, 1573 abrigavam emissoras de rádio. Quase a totalidade do território é atingido pela radiodifusão.

Gomes (2005: 347) se remete a topologia do sistema de rádio brasileiro, em sua espessura e no alcance de sua rede nos anos 1990:

Contando com a implantação de seus troncos de ligações interestaduais e estações repetidoras dispostas a distância variáveis, o sistema de rádio pode ser hoje parcialmente estimado pelos 23,9 mil quilômetros de microondas e 232,5 mil quilômetros de canais de freqüência existentes em 1997 e por uma base digital de operações em contínuo progresso.

Segundo informações do IBGE (2004), 89,3\% dos domicílios brasileiros possuíam rádio e $90 \%$ das pessoas entre 10 e 65 anos, vivendo em cidades, o escutam diariamente. Magnoni (1999: 42) lembra que "o rádio é o veículo de comunicação que tem maior público diurno e a maior popularidade entre as grandes camadas urbanas". Segundo Lucca (2002) se utilizando de informações do IBOPE (Instituto Brasileiro de Opinião Pública), são cerca de 115 milhões de rádio-ouvintes, recebendo em média quase quatro horas de mensagens por dia: de notícias a músicas.

A densa presença do circuito FM desde então nas grandes cidades brasileiras nos faz indagar o quão eficaz é a "catequese musical" contemporânea. São nessas aglomerações urbanas que o circuito de radio FM, e a produção fonográfica que lhe é vinculada em torno de um repertório médio, podem tirar maior proveito da influência imediata no circuito sonoro, a partir do conteúdo recebido pelo ouvinte.

\section{O dial FM de Campinas: elementos para uma análise geográfica da radiodifusão}

O dial de FM é composto pelas emissoras correspondentes ao conjunto dos canais disponíveis para recepção em uma determinada área a partir do espectro de FM. Tratam-se de canais comerciais, exceto o reservado para uma emissora comunitária, de acordo com o programa Radcom (Lei Municipal de Campinas No 12.017 de 01 de julho de 2004).

Geo UERJ. Rio de Janeiro - Ano 16, no . 25, v.2, $2^{\text {o }}$ semestre de 2014, pp.209-230

ISSN: 1415-7543 E-ISSN: 1981-9021

http://www.e-publicacoes.uerj.br/index.php/geouerj 
Do ponto de vista do sistema técnico, destacamos que todos os canais têm ligação com uma torre, o fixo que emite o sinal em razão de sua potência embutida. Dessa maneira, cada frequência é preenchida por diversos canais, recebidos em determinadas parcelas do território, pois emitidos a partir de uma respectiva localidade.

Desde o início da expansão do sistema de FM, a região de Campinas dispõe de um conteúdo técnico e informacional adequado para a difusão do novo circuito. A Região, em especial a partir da década de 1970, experimenta o processo de metropolização, sendo este tributário de São Paulo. Nesse período, a conurbação de Campinas com municípios vizinhos ganha força: a contigüidade entre essas cidades aponta para a gênese do que viria a ser institucionalizado em 2001 como Região Metropolitana de Campinas (RMC). Das aproximadamente sessenta emissoras que constituem o dial campineiro atual (Figura 1), vinte e duas se localizam na RMC, dezesseis delas no município de Campinas. A topologia indica ainda uma concentração de sinais provenientes da capital paulista.

Figura 1- O dial FM campineiro (2008): origem das emissoras

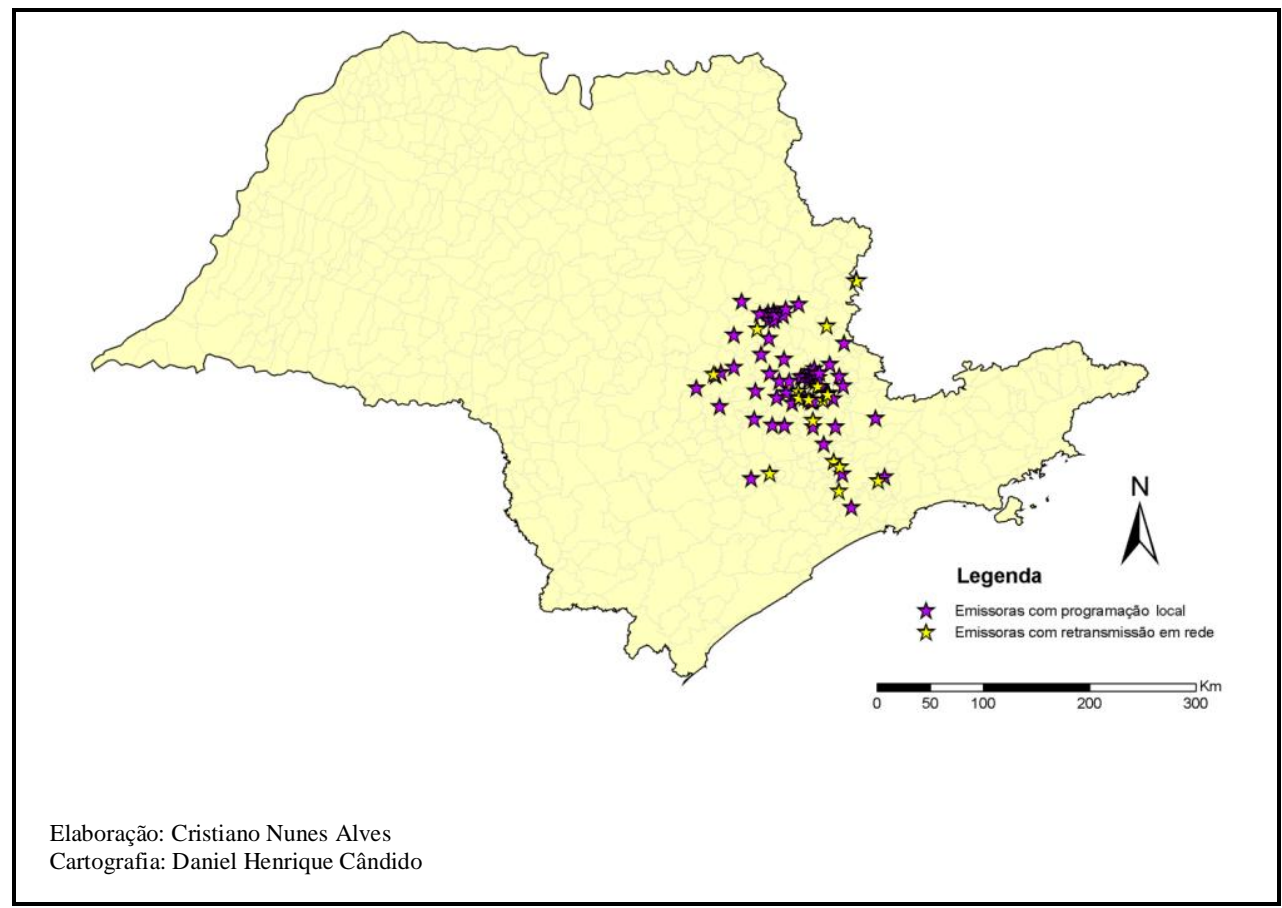

De acordo com a legislação federal as emissoras são divididas em classes de 
potência. A essas classes associam-se categorias de abrangências, definidas normativamente: comunitária, local e regional.

Estas distâncias podem variar tanto de acordo com as condições geográficas de uma dada região, bem como de acordo com a estrutura da emissora ou a qualidade do receptor de sinal. Tais valores de distância correspondem a aproximadamente ao local onde o sinal da emissora começa a falhar. Desta maneira há áreas de difusão com sinal fraco para cada um dos canais, como há também áreas de contato entre um e outro sinal, causando interferência, como, por exemplo, no caso do choque entre emissoras que ocupem a mesma freqüência, porém em canais de diferentes localidades.

Assim a 89 FM (89.3), concessão com perda de sinal prevista a partir de 24 quilômetros, atinge mais que o dobro do previsto e chega a 80 municípios, incluindo a região de Poços de Caldas-MG. Por sua vez, a Rádio Cidade (92.5 FM), emissora com perda de sinal prevista para 40 quilômetros, atinge 163 municípios num raio aproximado de 150 quilômetros.

Como se observa, a regulamentação, prevê abrangências que na realidade, são alteradas em virtude de fatores que vão desde a topografia até o poder econômico de um grupo de informação. Na verdade, a abrangência da difusão é resultado direto da potência técnica e da ação política de cada emissora; desse modo temos no dial a confluência de rádios de abrangência nacional, como as emissoras em rede, entre as quais a Transamérica de Mogi Mirim (93.9 FM); as rádios de abrangência regional, como a Rádio Educadora de Campinas (91.7 FM); as rádios de abrangência local, caso da Rádio Líder de Sumaré (105.5 FM). Esse contexto nos permite pensar em uma tipologia-topologia das rádios de acordo com a área compreendida pelo seu sinal.

A propagação da FM pelo ar implica na variação do sinal de acordo com a elevação do local da torre e mesmo de acordo com as condições atmosféricas de uma determinada área, ou seja: o sítio por vezes é decisivo. No caso da Região de Campinas destaca-se a Serra do Japi, que abriga torres de transmissão que conferem maior abrangência ao sinal, caso, entre outros, da Rede logos FM (97.3), frequiência de Itatiba ligada à Rede CBS.

Relatos do nosso campo de informação primária apontam, por exemplo, que o sinal da Rádio Laser de Campinas (93.3) é mais fraco quando chega às cidades do sul de Minas Gerais situadas nas áreas de relevo mais acidentado, próximas à divisa com São 
Paulo. Ocorrem também interferências de emissoras de maior potência localizadas em Belo-Horizonte, como a Itatiaia FM, que, assim como a Rádio Laser, é especializada em "sertanejo classe A."

É ainda em virtude da abrangência do sinal que uma determinada emissora de rádio pode ter direcionada a sua programação para esta ou aquela cidade, optando por atingir um público local, como a Rádio Clip de Indaiatuba (88.7 FM); ou de outras cidades, caso da Rádio Líder de Sumaré (105.5 FM), redirecionada a partir de Campinas, com programação mais voltada para o entorno campineiro do que para a própria cidade. Desenvolvem-se assim, a partir das rádios, estratégias de usos do território, que constituem relações imbricadas entre diferentes lugares e demonstram a complexidade do circuito. A Rádio Bandeirantes de São Paulo antes tinha a torre de transmissão no Pico do Jaraguá, direcionada ao interior, mas decidiu verter para a Grande capital, mudando a Antena para a Avenida Paulista, direcionando seu sinal para a capital paulista e o litoral. O Pico do Jaraguá passou a ser uma barreira para a difusão do sinal no interior de São Paulo.

Como resultado da segmentação de mercados e das relações entre os agentes do circuito em meio ao processo de adensamento urbano, redefine-se a ocupação dos canais e o conjunto dos lugares que uma rádio alcança ao longo do tempo, bem como os conteúdos transmitidos.

A Rádio União de Mogi Guaçu (89.9 FM), passava a transmitir na íntegra em maio de 1995, via satélite, a programação da FM paulistana Jovem Pan 2, a mais ouvida da capital segundo o IBOPE (Instituto Brasileiro de Opinião Pública), inserindo spots de anunciantes da região. A rádio de Mogi tinha na ocasião 50 kilowatts e era captada em 200 cidades com audiência de seis milhões de pessoas. Interessante também é o caso da Rádio Transamérica FM, que a partir de 1998 teve metade da programação regional, produzida em Mogi Mirim e a outra metade produzida a partir de três estúdios da capital paulista. Mais uma vez se mostra que em torno da radiodifusão, há uma hierarquização entre os lugares e a produção de escalas de acordo com os interesses de determinados agentes, conforme Raffestin (1993) e Smith (1988 [1984], 1999).

A ocupação dos canais não é, portanto, uma situação regular e constante no dial: na cidade de Campinas, no ano de 2001, foi criada a Rádio CBN (99.1 FM), no lugar da Rádio Cultura. No ano 2007 surge a 89 FM (89.3), no lugar da rádio Rock. Ocorreram 
recentemente no dial, ainda, o arrendamento para a Igreja Universal das rádios Morena e Planalto, em Campinas (2002) e Jundiaí (2003), respectivamente.

Criada na Cidade de São Paulo em 1963, a Rádio Scalla FM passou a atingir Campinas em 2005: o sinal já difundido há décadas a partir da capital paulista na frequência 92.5 chega à cidade por meio de uma retransmissora no canal $98.3 \mathrm{Mhz}$ em Sumaré. Mudam as emissoras que ocupam uma mesma concessão: em Campinas, no canal 99.1, atual CBN, operaram a "Sucesso" que se tornou "99" e em seguida a Cultura. A concessão original da Rádio Andorinhas (103.7 FM), é ocupada pela Rádio Antena 1 e, desde 1996, pertence à Rede Nova FM: "no decorrer dos anos, a concessão foi assumida e repassada para outros. Nesse processo a emissora mudou de nome duas vezes: na década de 1980, para Antena 1 e nos anos 90, para Nova Brasil FM" (ROLDÃO, 2007:13)

As solicitações de mudança de potência também fazem parte desse contexto e, em geral, decorrem do rearranjo nas empresas de informação, como no caso da fusão ocorrida, em 2007, entre os grupos Bandeirantes e GC2, detentores entre outros, das redes 89, Nativa e Alpha. A ampliação do sinal resulta num maior número de lugares acessados e no ganho com as divisas provenientes da publicidade. Trata-se dos bastidores do poder em torno dos meios de informação de massa, e, em geral, os grandes grupos de informação se beneficiam destas modificações normativas.

Vários fluxos de redes nacionais incidem também sobre a região de Campinas em busca da audiência segmentada, atomizada na escala nacional a partir da retransmissão via satélite; Eis uma tendência apontada como preponderante por empresários do setor. As emissoras em rede que compõem o dial trazem "informações descendentes", controladas por agentes externos que se instalam em grandes aglomerações urbanas.

Atualmente, a cidade de Campinas conta com retransmissoras das principais redes FM do Brasil, tais como a Jovem Pan, a Nova FM, a Antena 1, a CBN, a Aleluia, a Mix e a Scalla. A transmissão em rede compreende a igualdade de conteúdo e não o pertencimento ao mesmo grupo controlador. A Rede Nova FM, por exemplo, é composta por um conjunto de emissoras pertencentes a diversos grupos de informação, que unificaram conteúdo, operando numa espécie de franquia com a marca da rede.

Dados de 2007 indicam que 23 emissoras do dial de Campinas são elos para 
difusão de diversas redes de rádio do país, retransmitindo conteúdos de programação. Entre as redes no dial campineiro, a Jovem Pan é a que detém o maior número de emissoras, com quatro canais (Figura 2), seguida da Rede Aleluia e Antena 1, respectivamente com três e dois canais.

\section{Figura 2- O dial FM campineiro (2008): Alcance da Rede Jovem Pan}

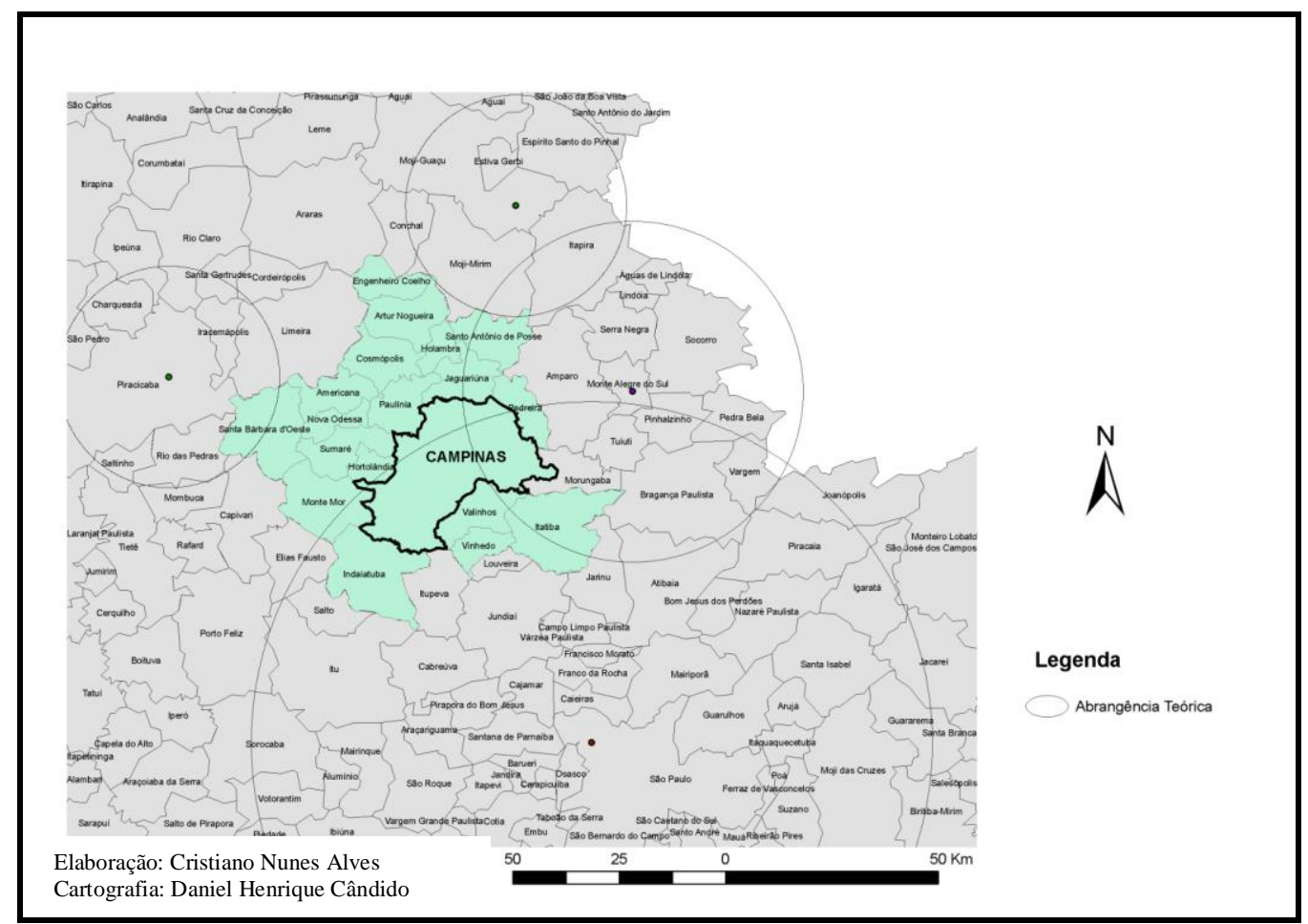

Em resumo: por meio de uma série de redes de rádio, busca-se, em aglomerações urbanas distintas, e de acordo com o segmento de mercado, uma determinada parcela de ouvintes classificados por hábitos, idade e, sobretudo, poder aquisitivo. Na segmentação da programação musical no dial campineiro, o segmento popular predomina em 30 emissoras, seguido do segmento religioso, presente em 14 emissoras.

\section{O circuito de FM campineiro: caracterização das emissoras concessionadas}

Expomos a seguir os aspetos produtivos do circuito composto pelo conjunto das 
emissoras de Campinas (Quadro Síntese 1). O critério para análise foi a existência de um fixo da emissora na cidade de Campinas, diferente do "dial": conjunto de canais recebidos em território campineiro, este composto por cerca de sessenta canais conforme entrevisto.

\section{Quadro Síntese 1 - O circuito de Rádio FM de Campinas: aspectos produtivos da} empresa e sistemas técnicos acionados

\begin{tabular}{|c|c|c|c|c|c|c|c|c|c|}
\hline \multicolumn{7}{|c|}{ Mercado e densidade normativa } & \multicolumn{3}{|c|}{ Fixos e trabalho (formas e funçôes) } \\
\hline \multirow{2}{*}{$\begin{array}{l}\text { Empresa } \\
\text { Rede } \\
\text { Proprietáno }\end{array}$} & \multirow{2}{*}{$\begin{array}{c}\text { Emissora } \\
\text { Frequiência Mhz }\end{array}$} & \multirow{2}{*}{$\begin{array}{l}\text { Aspectos da rede } \\
\text { Origem da programação }\end{array}$} & \multirow{2}{*}{$\begin{array}{c}\text { Sogpanasto do } \\
\text { marcado }\end{array}$} & \multirow{2}{*}{$\begin{array}{l}\text { Origem da } \\
\text { concessão }\end{array}$} & \multicolumn{2}{|c|}{ Alcance da difusão } & \multirow{2}{*}{$\begin{array}{l}\text { Torre de } \\
\text { transmissão }\end{array}$} & \multirow{2}{*}{$\begin{array}{l}\text { Estrutura da emissora em campinas (composição } \\
\text { interna da empresa: departamentos, estúdios e } \\
\text { aspectos do fixo) }\end{array}$} & \multirow{2}{*}{\begin{tabular}{|c} 
Pessoal \\
empregado \\
por \\
emissora \\
TOTAL \\
DO \\
CIRCTITo \\
93 \\
\end{tabular}} \\
\hline & & & & & \begin{tabular}{|c|}
$\begin{array}{c}\text { Classe } \\
\text { de } \\
\text { potência }\end{array}$ \\
\end{tabular} & $\begin{array}{l}\text { (Abrangênci } \\
\text { a teórica emm } \\
\text { quilômetros) }\end{array}$ & & & \\
\hline \multirow{3}{*}{$\begin{array}{ll}\text { Grupo } & \text { Cidade- } \\
\text { Laser } & \text { (Odilon } \\
\text { Gareia) } & \end{array}$} & CIDADE 92.5 & Transmissão a partir de Campinas & Popular & Campinas-SP & A 1 & 40 & Campinas-SP & \multirow[t]{2}{*}{$\begin{array}{l}\text { - Toda estrutura da emissora. } \\
\text { - Mesmo prédio para as três emissoras } \\
\text { do grupo, no Jardim Săo Gabriel. }\end{array}$} & \multirow{3}{*}{9} \\
\hline & LASER 93.3 & Transmissão a partir de Campinas & Popular & Valinhos-SP & A 1 & 40 & Campinas-SP & & \\
\hline & MIX 97.5 & \begin{tabular}{|l|} 
Retransmisão da cidade de São \\
Paulo (inserçẫo de anúncios \\
locais)
\end{tabular} & \begin{tabular}{|l|} 
Jovem \\
\end{tabular} & Itu-SP & A 1 & 40 & Itupeva-SP & $\begin{array}{l}\text { - Departamento comercial } \\
\text { - Estridio para spots }\end{array}$ & \\
\hline \multirow{3}{*}{$\begin{array}{l}\text { Grupo } \\
\text { Comunicações } \\
\text { Brasil SAT }\end{array}$} & KISS 107.9 & $\begin{array}{l}\text { Retransmisão da cidade de } \\
\text { Cosmópolis (inserção de anúncios } \\
\text { regionais) }\end{array}$ & Jovem & $\begin{array}{l}\text { Cosmópolis- } \\
\text { SP }\end{array}$ & $\mathrm{C}$ & 7 & Cosmópolis-SP & \multirow{3}{*}{$\begin{array}{l}\text { - Departamento comercial } \\
\text { - Estúdio para spots } \\
\text { - Mesmo prédio no centro para as três emissoras do } \\
\text { gupo e o canal } 36 \text { de TV UHF, desde } 2004 \text {. }\end{array}$} & \multirow{3}{*}{7} \\
\hline & TUPI 96.5 & \begin{tabular}{|l|}
$\begin{array}{l}\text { Retransmisão da cidade de São } \\
\text { Paulo (inserção de anúncios } \\
\text { regionais) }\end{array}$
\end{tabular} & \begin{tabular}{|l|} 
Popular \\
\end{tabular} & \begin{tabular}{|l|}
$\begin{array}{l}\text { Santo } \\
\text { Antônio } \\
\text { Posse-SP }\end{array}$ \\
\end{tabular} & B 1 & 16 & \begin{tabular}{|l|}
$\begin{array}{l}\text { Santo } \\
\text { de Posse-SP }\end{array}$ \\
\end{tabular} & & \\
\hline & SCALLA 96.9 & $\begin{array}{l}\text { Retransmisão da cidade de São } \\
\text { Paulo (inserção de anúncios } \\
\text { locais). }\end{array}$ & Adulto & $\begin{array}{l}\text { Hortolândia- } \\
\text { SP }\end{array}$ & $\mathrm{C}$ & 7 & Hortolândia-SP & & \\
\hline $\begin{array}{l}\text { Grupo Nova - } \\
\text { Rede Central de } \\
\text { Comunicaçōes } \\
\text { (Orestes Quércia) } \\
\end{array}$ & $\begin{array}{l}\text { NOVA BRASIL } \\
103.7\end{array}$ & \begin{tabular}{|l|} 
Retransmissão do conteúdo da \\
Rede Nova (via satelite)
\end{tabular} & Adulto & Campinas-SP & A 1 & 40 & Campinas-SP & $\begin{array}{l}\text { - Estúdio para spots, no mesmo prédio da Rádio } \\
\text { Central AM } 870 \mathrm{Khz} \text {, no Jardim Leonor. }\end{array}$ & 1 \\
\hline $\begin{array}{l}\text { Reder Aleluia } \\
\text { (arrendada junto a } \\
\text { Natal Gale) }\end{array}$ & MORENA 100.3 & $\begin{array}{l}\begin{array}{l}\text { Retransmissão do conteúdo da } \\
\text { Rede Aleluia } \\
\text { (inserção de anúncios e pregações } \\
\text { locais) }\end{array} \\
\end{array}$ & Religioso & Campinas-SP & A 2 & 36 & Campinas-SP & $\begin{array}{l}\text { - Toda estrutura da emissora no mesmo prédio da } \\
\text { Rádio Jequitibá AM } 1230 \mathrm{Khz} \text { no Jardim } \\
\text { Chapadão. }\end{array}$ & 8 \\
\hline Grupo Antena 1 & ANTENA 1107.5 & \begin{tabular}{|l|} 
Retransmissão do conteúdo da \\
Rede Via Satélite Antena \\
(inserçâo de anúncios locais)
\end{tabular} & Adulto & Indaiatuba-SP & A 1 & 40 & Campinas-SP & - Departamento comercial no Bairro Cambuí. & 10 \\
\hline $\begin{array}{l}\text { Rede } \\
\text { Metropolitana }\end{array}$ & LÍDER 105.5 & 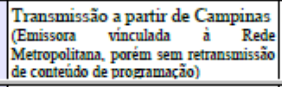 & Popular & Sumaré-SP & B 2 & 12 & Sumaré-SP & - Toda estrutura da emissora no Bairro Castelo. & 8 \\
\hline \begin{tabular}{|l} 
Grupo \\
Bandeirantes
\end{tabular} & $\begin{array}{l}\text { EDUCADORA } \\
91.7\end{array}$ & Transmissão a partir de Campinas. & Jovem & Campinas-SP & A 1 & 40 & Campinas-SP & \begin{tabular}{|l|} 
- Toda estrutura da emissora. \\
- Prédio do Complexo da Rede Bandeirantes no \\
Jardim São Gabriel
\end{tabular} & 15 \\
\hline Rede Jovem Pan & \begin{tabular}{|l} 
JOVEM PAN \\
89.9
\end{tabular} & $\begin{array}{l}\text { Retransmissão do conteúdo da } \\
\text { Rede Jovem Pan } \\
\text { (inserção de anúncios locais) }\end{array}$ & Jovem & \begin{tabular}{|l|} 
Águas de \\
Lindóia-SP
\end{tabular} & B 1 & 16 & Sena Negra-SP & - Departamento comercial no Jardim Flamboyant. & 3 \\
\hline Grupo Alpha & 89 FM 89.3 & \begin{tabular}{|l|} 
Transmissão a partir Campinas \\
\end{tabular} & Jovem & Amparo-SP & A 4 & 24 & Campinas-SP & - Toda estrutura da emissora no Jardim Chapadão. & 18 \\
\hline Rede Globo & CBN 99.1 & $\begin{array}{l}\text { Retransmissão do conteúdo da } \\
\text { Rede CBN de noticias Parcela da } \\
\text { programação transmitida a partir } \\
\text { de Campinas }\end{array}$ & $\begin{array}{l}\begin{array}{l}\text { Adulto } \\
\text { (noticias) }\end{array} \\
\end{array}$ & Campinas-SP & A 3 & 31 & Campinas-SP & $\begin{array}{l}\text { - Toda estrutura da emissora no mesmo prédio da } \\
\text { Rádio Brasil AM } 1270 \mathrm{Khz} \text {, no centro da cidade. }\end{array}$ & $\begin{array}{l}\text { Sem } \\
\text { informagsho }\end{array}$ \\
\hline \begin{tabular}{|l} 
Rede \\
Evangélica \\
Maranatha
\end{tabular} & $\begin{array}{l}\text { MARANATA } \\
106.1\end{array}$ & $\begin{array}{l}\text { Retransmissão do conteúdo da } \\
\text { Rede Maranatha. Parcela da } \\
\text { programação transmitida a partir } \\
\text { de Campinas }\end{array}$ & Religioso & Campinas-SP & B 2 & 12 & Campinas-SP & $\begin{array}{l}\text { - Estúdio de transmissão, numa casa no Jardim } \\
\text { Itatiaia }\end{array}$ & 4 \\
\hline \begin{tabular}{|l|} 
Prefeitura \\
Muncipal \\
Campinas \\
\end{tabular} & \begin{tabular}{|l} 
RÁDIO \\
EDUCATIVA \\
101.9
\end{tabular} & Transmissão a partir de Campinas & Adulto & Campinas-SP & $\mathrm{Bl}$ & 16 & Campinas-SP & $\begin{array}{l}\text { - Toda estrutura da emissora. } \\
\text { - Estridio de transmissão na Torre do Castelo }\end{array}$ & 10 \\
\hline
\end{tabular}

Fonte: Campo de informação primária

Campinas abriga atualmente dezesseis emissoras concessionadas, ligadas a 12 grupos de informação, exceto a Rádio Educativa, que pertence à Prefeitura Municipal

Geo UERJ. Rio de Janeiro - Ano 16, ${ }^{\circ}$. 25, v.2, $2^{\circ}$ semestre de 2014, pp.209-230

ISSN: 1415-7543 E-ISSN: 1981-9021

http://www.e-publicacoes.uerj.br/index.php/geouerj 
(Figura 3).

Figura 3 - O circuito FM de Campinas (2008) - emissoras concessionadas.

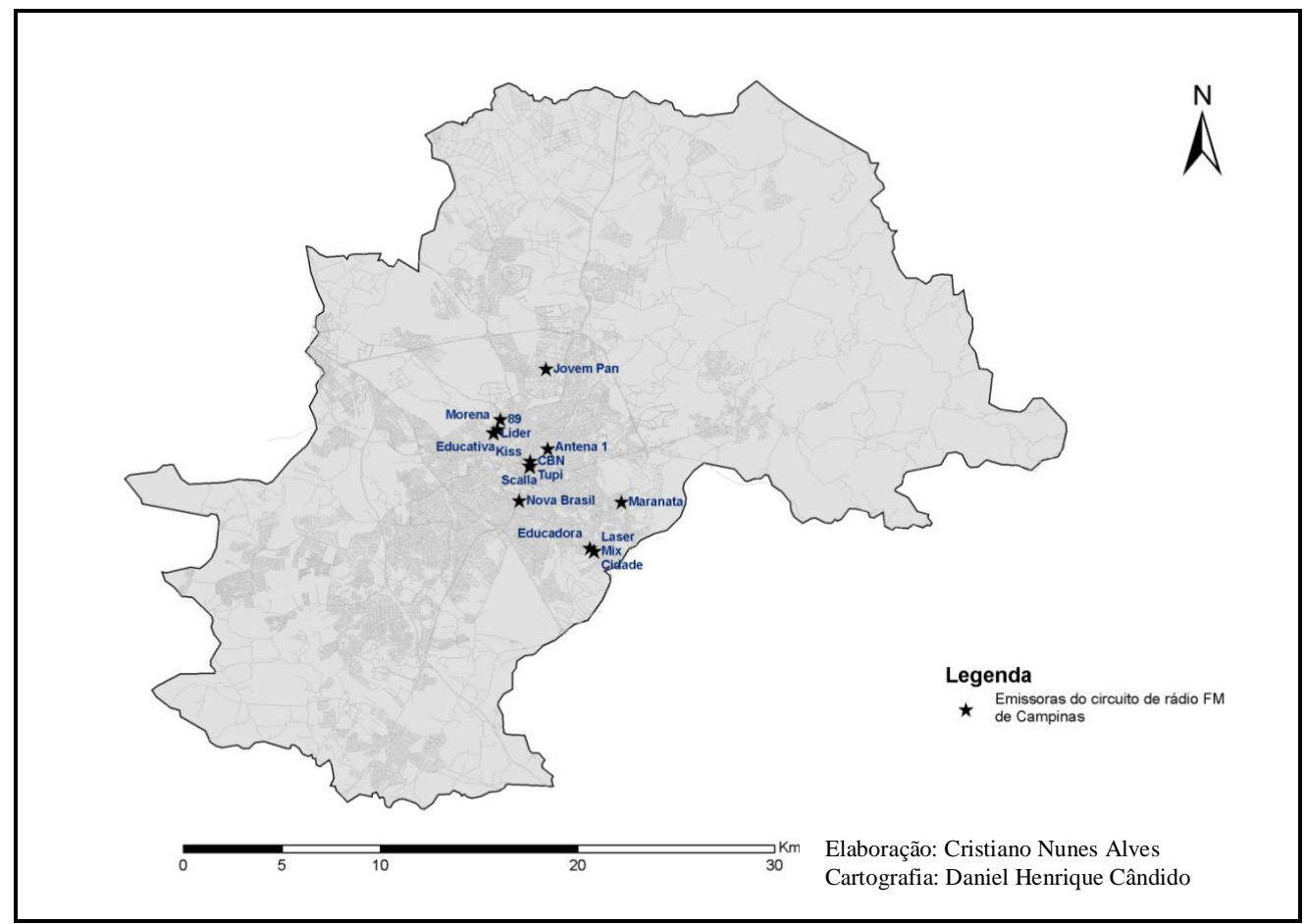

Nove emissoras são, na verdade, concessões outorgadas a outros municípios, redirecionadas a partir da cidade de Campinas. Dez emissoras operam em rede e seis transmitem conteúdos a partir de Campinas, município de considerável densidade de sinais de rádio FM (Figura 4). 
Figura 4 - O circuito FM de Campinas (2008) - Torres de transmissão e potências relacionadas.

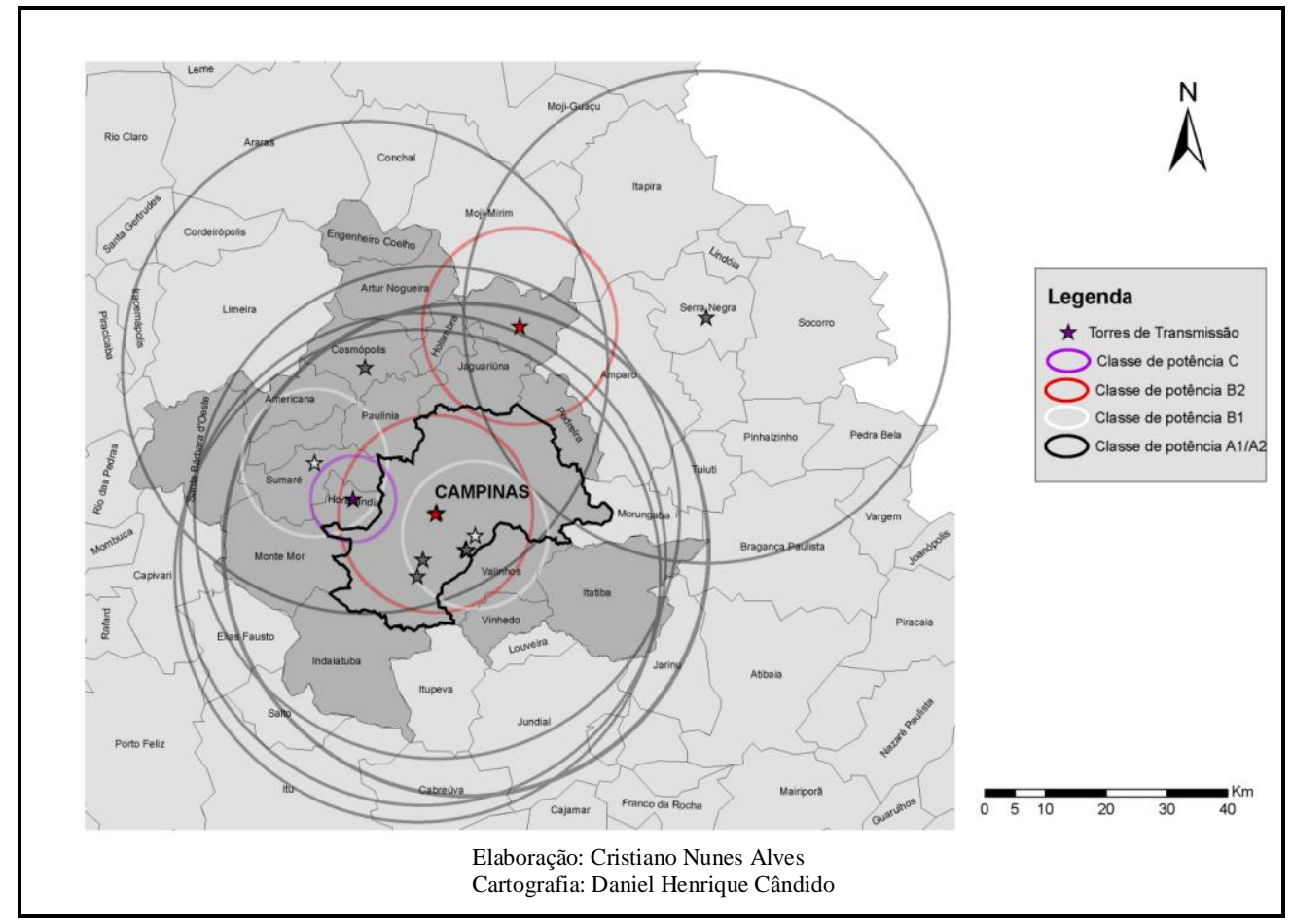

Além da Educativa, direcionada ao segmento adulto, outras cinco programações são produzidas localmente: Laser, Cidade e Líder atuam no segmento popular, enquanto Educadora e 89 FM são direcionadas ao público jovem.

No que tange à estrutura interna das emissoras do circuito, nosso campo de informação primária, apontou que sete delas abrigam a composição completa da empresa, com estúdio de transmissão e estrutura interna associada: departamento comercial, jornalístico, de promoção, entre outros.

Contam somente com o departamento comercial e/ou estúdio para spots, outras sete emissoras. Nesses casos o vínculo da programação com Campinas se estabelece por meio de anúncios locais, inseridos em meio a conteúdos produzidos via satélite ou retransmitidos a partir de outra emissora, em geral da capital paulista.

Ainda conforme nosso campo de informação primária apurou-se, que os vínculos empregatícios se distinguem entre as emissoras. $\mathrm{Na}$ Educadora os trabalhadores são contratados por meio da Consolidação das Leis do Trabalho. São 
comuns as horas extras e uma jornada de trabalho que pode chegar a 12 horas por dia, com uma folga prevista por semana. Por sua vez, na Rádio Líder, atesta um de seus locutores, a maioria dos vínculos ocorre por meio de trabalhos de eventuais (freelancers), contratos verbais e demais relações fundadas na proximidade entre os agentes.

As informações primárias davam conta ainda, que o circuito empregava 93 pessoas na cidade de Campinas no ano de 2008, número que, ao que tudo indica, fora bem maior outrora. A precarização do trabalho no rádio é apontada por grande parcela dos funcionários com os quais conversamos, como um dos obstáculos para uma programação de rádio de maior qualidade.

A crescente utilização das novas tecnologias de informação é uma tendência no rádio atual presente no circuito FM campineiro, relacionada com essa precarizaçãoredução da estrutura das emissoras. Em 1992, a Rádio Nova Brasil FM Campinas contava com dez funcionários: cinco locutores, dois produtores comerciais, um programador, um motorista e um coordenador artístico. Hoje a emissora tem apenas um funcionário que acumula as funções de programador e produtor comercial.

A Rádio Maranata se localiza numa residência no Jardim Itatiaia, área de maior altitude, e conta apenas com o estúdio de transmissão, improvisado em um dos cômodos da casa. Completando o circuito, a Rádio Morena dispõe de toda a estrutura alocada, porém, retransmite o conteúdo da Rede Aleluia em virtude de arrendamento junto a Igreja Universal.

Nas emissoras de rádio, os intervalos vendáveis à publicidade compreendem uma série de categorias e o comercial padrão tem trinta segundos. Existem inserções de propaganda que dispensam um registro sonoro prévio, caso das chamadas e locuções ao longo dos programas.

De maneira diferente, os spots e os jingles necessitam desse registro sonoro prévio. O spot é um dos espaços vendáveis para publicidade. Ele pode ou não ser musicado, e traz a narrativa da propaganda a ser divulgada. O jingle, por outro lado, é uma peça publicitária necessariamente musicada de fácil assimilação pelo público alvo na qual se vincula a propaganda de um produto, serviço, marca ou empresa.

Para a produção desses tipos de comerciais, os estúdios fonográficos são acionados. A agência de publicidade, em geral, é mediadora na negociação. O cliente procura a agência e explica o que intenta para veicular a propaganda. A agência prepara 
um roteiro, chamado no meio publicitário de briefing e o encaminha ao estúdio. Após apreciação da proposta, e em caso afirmativo por parte do cliente, inicia-se a produção do fonograma.

Mas os spots e jingles também são produzidos por emissoras. Em Campinas apenas a Antena 1 não tem estrutura para produzir fonogramas em seu fixo. Inclusive rádios que operam apenas com o departamento comercial oferecem essa opção: é o caso da Jovem Pan do Grupo CBS.

Agentes do circuito de FM explicam que no caso dos anunciantes maiores os comerciais são elaborados na cidade de São Paulo. No caso de anunciantes regionais e locais, não raro ocorre a captação de um cliente de maneira direta, portanto sem mediação da agência de publicidade. Entre os profissionais se reconhece que o jingle da rádio é de menor qualidade e que a tendência é que no futuro as rádios não realizem mais esse trabalho.

Dados do IBOPE de agosto de 2006 indicavam que, no Brasil, na audiência total do rádio $82 \%$ se dirigia para FM e $18 \%$ para AM. A menor audiência implica em anúncios menores, sendo comum a utilização do termo "anunciantes de AM" para designar uma parcela de anunciantes locais, como postos de gasolina, supermercados, motéis, entre outros, que aderem ao circuito FM. A quantidade de anunciantes varia, mas, segundo nosso campo de informação, pode-se afirmar a existência de algumas dezenas de anunciantes para cada uma das rádios. Os contratos podem chegar até dois anos, todavia a negociação para a manutenção dá-se a cada trimestre ou até mesmo mensalmente.

Como podemos observar, na divisão do trabalho do circuito (Quadro 1), um estúdio produz o material publicitário, numa situação que é em geral, intermediada pela agência de publicidade. Ao processo de criação concorrem dois agentes: a própria emissora e o estúdio fonográfico, muitos dos quais especializados em publicidade.

\section{Quadro 1}

\begin{tabular}{|c|c|}
\hline $\begin{array}{c}\text { O circuito FM: divisão do trabalho na produção e no comércio de } \\
\text { fonogramas publicitários }\end{array}$ \\
\hline Agente - fixo & Função \\
\hline Emissora & Difusão do comercial \\
\hline
\end{tabular}

Geo UERJ. Rio de Janeiro - Ano 16, no . 25, v.2, $2^{\text {o }}$ semestre de 2014, pp.209-230

ISSN: 1415-7543 E-ISSN: 1981-9021

http://www.e-publicacoes.uerj.br/index.php/geouerj 


\begin{tabular}{|c|c|}
\hline \multicolumn{2}{|c|}{$\begin{array}{c}\text { O circuito FM: divisão do trabalho na produção e no comércio de } \\
\text { fonogramas publicitários }\end{array}$} \\
\hline Estúdio da emissora & $\begin{array}{r}\text { Produção do comercial (registro } \\
\text { fonográfico do material publicitário) }\end{array}$ \\
\cline { 1 - 2 } Estúdio fonográfico especializado & Mediação entre produtores e anunciantes \\
\hline Agência de publicidade & Solicitação de material publicitário \\
\hline Anunciante
\end{tabular}

Fonte: Campo de informação primária

Importa-nos ressaltar a propaganda como um dos elos do circuito, produtora de diferentes escalas de valor para cada aglomeração urbana, cada porção do território. Nesse sentido, lançamos o olhar para o caso da Jovem Pan e da Antena 1, duas emissoras que mantém apenas o departamento comercial em Campinas. Esses dados podem ajudar a aclarar importantes desdobramentos espaciais do circuito sonoro.

A Rede Antena 1 cobre aproximadamente $46 \%$ do território nacional, chegando a 696 municípios e contabilizando em média 2.630 .000 ouvintes por minuto. Direcionada ao ouvinte "classe A, com mais de 25 anos", a Rede Antena 1 foi fundada na década de 1970 pelo Grupo Antena Uno da Itália. Atualmente a Rede conta com 18 emissoras afiliadas e seis próprias, incluindo "os principais mercados como São Paulo, Porto Alegre, Campinas, Belo Horizonte, Brasília, Goiânia, e Vale do Paraíba” (Rede Antena 1 - material promocional).

A emissora Antena 1 tem a sua torre na saída sul da cidade, às margens da Rodovia Santos Dumont, e o seu sinal atinge 102 municípios, área potencial para os anunciantes. O departamento comercial, composto por 10 funcionários, se localiza no Bairro Cambuí, área valorizada da cidade. A opção pela localização, explica Débora, agente comercial da emissora, é em virtude do tipo de anunciante, justamente aquele que negocia com o público classe. A Scalla também é direcionada ao "público classe A", algo sublinhado no seu material promocional, conforme o texto a seguir " $A$ rádio Scalla FM localiza-se na Avenida Paulista, um dos maiores centros empresariais e culturais do país. Uma das maiores cidades do mundo”.

Os dados abaixo, fornecidos pelo departamento comercial da Jovem Pan em Campinas trazem outros elementos para melhor compreender a maneira como o território é repartido pelas redes de informação a partir da publicidade.

A Rede Jovem Pan FM engloba 51 emissoras filiadas no Brasil e uma na 
Argentina que retransmitem o mesmo conteúdo apenas com a inserção de comercial regional e local e, em alguns casos, como em Campinas, uma equipe de promoção é acionada para prestação de serviços eventuais. Os intervalos de tempo da programação são vendidos a preços que variam de acordo com cada lugar em que haja uma emissora da rede. Nessa emissora não necessariamente haverá um estúdio de transmissão, ao contrário do departamento comercial que existe, e é responsável por vender os anúncios e se necessário os produzir. Para inserção do comercial padrão de 30 segundos num horário determinado, os preços variam de $\mathrm{R} \$ 12,00$ em Barra Bonita-SP, até $\mathrm{R} \$$ 1.641,15 na cidade de São Paulo. Esses preços variam ainda de acordo com a região do país. Para se ter uma ideia, o maior preço na região nordeste é o do anúncio em Recife$P E$ que custa $R \$ 264,00$. A emissora em Campinas cobre 30 municípios e os preços são os seguintes: das 6 às 24 horas o valor cobrado é de $\mathrm{R} \$ 100,00$ e das 06 às 19 horas é $\mathrm{R} \$ 144,00$, enquanto o horário pré-determinado custa $\mathrm{R} \$ 179,00$. O material promocional da Rede Jovem Pan indica a cobertura na Região do "Circuito das Águas", em Bragança Paulista, Itatiba e Atibaia, remetendo o possível anunciante ao poder de consumo desse público atingido pela emissora.

Trata-se de um preço diferencial para a propaganda de acordo com certos atributos do lugar: sua aglomeração (o mercado urbano) e a capacidade de compra da população. A transmissão em rede, por sua vez, exponencializa esse alcance e o seu custo: o preço por execução em toda a Rede Jovem Pan num horário determinado é de $\mathrm{R} \$ 5.639,27$.

Ocorre, deste modo, a repartição da população e dos lugares de acordo com um perfil de inserção no mercado, o que implica em uma determinada espacialização do circuito. Chegar a um maior número de lugares significa ter acesso a um maior mercado consumidor. Concentração humana e tamanho do mercado consumidor se tornam centrais para diferenciar o quanto vale esta ou aquela porção do território no circuito FM. Como bem lembra N. Smith (1999: 142) “a escala contém a atividade social e, ao mesmo tempo, proporciona uma geografia já dividida em compartimentos, na qual a atividade social tem lugar." Vê-se que as emissoras criam suas próprias escalas, dividindo e usando o território de acordo com as suas estratégias.

\section{Considerações Finais}

Geo UERJ. Rio de Janeiro - Ano 16, nº. 25, v.2, $2^{\circ}$ semestre de 2014, pp.209-230

ISSN: 1415-7543 E-ISSN: 1981-9021

http://www.e-publicacoes.uerj.br/index.php/geouerj 
O estudo da radiodifusão implica considerar que a recepção das informações ocorre sem defasagem temporal. Com as novas formas de interação entre as cidades, entre outros, decorrentes dos meios de informação esquizofônicos, regiões antes distantes espaço-temporalmente se mostraram apropriáveis por certos grupos (HARVEY, 1992). Senão vejamos: trata-se de um redutor extremo da fricção de distância, em virtude da sua capacidade de sobrepor-se ao distanciamento, deste modo, reconfigurando as condições de apropriação e domínio do espaço.

Apenas na década de 1990 define-se mais claramente o processo de influência dos grandes meios de informação sobre o circuito sonoro em Campinas, entre outros com a difusão massiva de um repertório médio.

Predomina a ação em rede no circuito de rádio FM estudado e a preponderância da publicidade como elo entre a radiodifusão e o registro fonográfico. Tais redes são controladas por grandes grupos de informação, vinculadores de conteúdos e/ou detentores de emissoras. Isto, pois, a operação das redes dá-se ainda por meio da propriedade da emissora, ocorrida sem a vinculação direta da marca do grupo via transmissão de conteúdo em rede.

É importante dizer que não se encerram as questões em torno do processo de influência sobre o circuito sonoro por meio dos mecanismos de enquadramento, pois sobre as discussões relacionadas às espessuras das densidades técnica e informacional e acima delas está a discussão sobre a comunicação em si.

A região estudada abriga uma considerável base ligada às formas-conteúdo técnico-informacionais que são, todavia, usadas em favor da cisão e da fragmentação territorial. A quem vale, então, toda essa luminosidade cegante?

Como resultado, ao invés de nos incitar, a cidade nos paralisa em um movimento, reeditado seja nas buzinas padronizadas ou nos sons previsíveis do circuito de rádio FM: anestesiam-nos de novas possibilidades para o território usado, tiram-nos também as sensações.

\section{Referências bibliográficas}

ADORNO, Theodor. Indústria cultural e sociedade. São Paulo: Paz e Terra, 2004 [1947]. $127 \mathrm{p}$.

Geo UERJ. Rio de Janeiro - Ano 16, nº. 25, v.2, $2^{\circ}$ semestre de 2014, pp.209-230

ISSN: 1415-7543 E-ISSN: 1981-9021

http://www.e-publicacoes.uerj.br/index.php/geouerj 
ALVES, Cristiano Nunes. O circuito sonoro: radiodifusão $F M$ e produção fonográfica em Campinas-SP. Dissertação de mestrado (Departamento de Geografia do Instituto de Geociências da Universidade Estadual de Campinas). Campinas. 2008. 161 p.

ANTONGIOVANNI, Lídia. O meio técnico-cientifico-informacional brasileiro: $a$ publicidade como um vetor das modernizações. Dissertação de mestrado (Departamento de Geografia da Faculdade de Filosofia Letras e Ciências Humanas), Universidade de São Paulo. São Paulo. 1999. 133 p.

CALDAS, Waldenyr. Luz néon: canção e cultura na cidade. São Paulo: SESC. 1995. $157 \mathrm{p}$.

CLAIRE, Guiu. Géographie et musique: état des lieux. Une proposition de synthèse. Geógraphie et Cultures, no 59, 2006. (pp. 7-26).

FRIEDMANN, Georges. Sete estudos sobre o homem e a técnica. São Paulo: Difel, 1968. $162 \mathrm{p}$.

GEIGER, Pedro Pinchas. Evolução da rede urbana brasileira. Rio de Janeiro: INEP, 1963. 2005. $455 \mathrm{p}$.

GOLDMANN, Lucien. A criação cultural na sociedade moderna. São Paulo: Difel, 1972. $117 \mathrm{p}$.

GOMES, Cilene. Telecomunicações, informática e informação e a remodelação do território brasileiro In SANTOS, Milton e SILVEIRA, María Laura. O Brasil: território e sociedade no início do século XXI. Rio de Janeiro: Record, 2005. (pp 345-356).

HARVEY, David. A Condição pós-moderna. São Paulo-SP: Edições Loyola, 1992 [1989]. 349 p.

HEITOR, Luis. Música e catequese. In Cultura Política, n 40, 1945. (pp. 140-148).

LUCCA, Silvia de. O produto musical nas rádios brasileiras e aspectos de sua influência: um panorama atual paulistano. Dissertação de mestrado apresentada a Escola de Comunicação e Artes da Universidade de São Paulo. São Paulo, 2002. 190 p. MAGNONI, Antônio (et all). O rádio digital avança no interior de São Paulo.In BIANCO, Nélia R. Del \& MOREIRA, Sônia Virginia (org). Rádio no Brasil: tendências e perspectivas. Rio de Janeiro/Distrito Federal: UERJ/UNB, 1999. (pp. 41-60).

MARIANO, Júlio. História da imprensa em Campinas. Campinas: Massaioli, 1972. 133 p.

MARTIGNONI, Andrea. Objets et paysages sonores. In Geógraphie et Cultures, $\mathrm{n}^{\circ}$ 59, 2006. (pp. 127-133).

ORTIZ, Renato. A moderna tradição brasileira. São Paulo: Brasiliense, 1989. 222 p.

PRED, Alan. Sistemas de cidades: economia adiantada, crescimento passado, processos presentes e opções de desenvolvimento futuro. Rio de Janeiro: Zahar, 1979. $230 \mathrm{p}$.

RAFFESTIN, Claude. Por uma geografia do poder. São Paulo-SP: Ática, 1993. 269 p. ROLDÃO, Ivete Cardoso do Carmo. CBN Campinas e Nova Brasil - as emissoras em rede de Campinas. Texto apresentado no XXX Congresso Brasileiro de Ciências da Comunicação. Santos, 2007. (15 páginas).

ROMAGNAN, Jean-Marie. La musique: un terrain nouveau pour les géographes. In Géographie et cultures, $\mathrm{n}^{\circ}$ 36, 2000. (pp. 107-126).

SALGADO, Álvaro. Radiodifusão fator social. In Revista Cultura Política. Rio de Janeiro, 1941 (pp. 79-93).

SANTOS, Milton. O território e o saber local: algumas categorias de análise In Cadernos IPPUR, ano XIII, n 2, 1999. (pp. 15-26).

SANTOS, Milton. A natureza do espaço: técnica e tempo, razão e emoção. São Paulo-

Geo UERJ. Rio de Janeiro - Ano 16, no . 25, v.2, $2^{\text {o }}$ semestre de 2014, pp.209-230

ISSN: 1415-7543 E-ISSN: 1981-9021

http://www.e-publicacoes.uerj.br/index.php/geouerj 
SP: Hucitec, 2004 [1996]. 384 p.

SANTOS, Milton e SILVEIRA, María Laura. O Brasil: território e sociedade no início do século XXI. Rio de Janeiro: Record, 2005 [2001]. 473 p.

SCHAFER. R. Murray. A afinação do mundo - uma exploração pioneira pela história passada e pelo atual estado do mais negligenciado aspecto do nosso ambiente: a paisagem sonora. São Paulo: Unesp, 1997 [1977]. 381 p.

SMITH, Neil. Desenvolvimento desigual: natureza, capital e a produção do espaço. Rio de Janeiro: Bertrand Brasil, 1988 [1984]. 250 p.

SMITH, Neil. Contornos de uma política espacializada: veículos dos sem-teto e produção de escala geográfica In ARANTES, Antônio (ORG). O Espaço da diferença. Rio de Janeiro, Papirus, 1999. (pp 132-175).

SODRÉ, Muniz. A comunicação do grotesco: um ensaio sobre a cultura de massas no Brasil. Petrópolis-RJ: Vozes, 1976. 83 p.

SODRÉ, Muniz. Reinventando a cultura: a comunicação e seus produtos. Rio de Janeiro: Vozes, 1999. 180 p.

Lei Municipal de Campinas $\mathrm{N}^{\mathrm{o}} 12.017$ de 01 de julho de 2004. Dispõe sobre o funcionamento das rádios comunitárias (Radcom) no município de Campinas e da outras providências.

INSTITUTO BRASILEIRO DE GEOGRAFIA E ESTATÍSTICA (IBGE). Estimativas populacionais para os municípios brasileiros em 01.07.2012. Disponível em www.ibge.gov.br (acesso em 12 de novembro de 2012).

Pesquisa Nacional por Amostra de Domicílios - 2004. Disponível em www.ibge.gov.br (acesso em 06 de novembro de 2012).

INSTITUTO BRASILEIRO DE OPINIÃO PÚBLICA (IBOPE). Relatório Rádio, agosto, 2006.

Artigo recebido para publicação em julho de 2014.

Artigo aceito para publicação em outubro de 2014. 